\title{
A Novel Mixed Method Using MM-SE with Change in Routhain Array for Model Order Reduction
}

\section{Aswant Kumar Sharma ( $\nabla$ aswantksharma@gmail.com )}

Rajasthan Technical University https://orcid.org/0000-0002-0246-2095

\section{Dhanesh Kumar Sambariya}

Rajasthan Technical University

\section{Research Article}

Keywords: Model order reduction, mixed-method, stability equation, moment matching, response indices.

Posted Date: October 29th, 2021

DOI: https://doi.org/10.21203/rs.3.rs-705686/v1

License: (9) This work is licensed under a Creative Commons Attribution 4.0 International License. Read Full License 


\title{
A Noval Mixed Method Using MM-SE with Change in Routhain Array for Model Order Reduction
}

\author{
Aswant Kumar Sharma and Dhanesh Kumar Sambariya \\ aswantksharma@gmail.com \\ Department of Electrical Engineering, Rajasthan Technical University, INDIA
}

\begin{abstract}
The system modelling leads towards the higher-order differential equations. These systems are difficult to analyse. Therefore, for ease and understanding, the conversion of higher to lower order is required. The model order reduction(MOR) is a systematic procedure to tackle these kinds of situations. This paper offers a mixed method for MOR using the modified moment matching (MM) and stability equation (SE). The modification is applied in the routhain array of MM. The approach has been verified by examining the error between the original, proposed and compared with reduced order available in the literature. The obtained result has been compared on the basis of step response characteristics and the response indices error.
\end{abstract}

Keywords: Model order reduction, mixed-method, stability equation, moment matching, response indices.

\section{Introduction}

The physical machine systems are of higher order .The mathematical complexity increases as the order of the system increases. The design analysis of a complex system is confusing and time-consuming.To remove mathematical complexity and make it simple, model reduction is the solution for higher-order differential equations. Model order reduction (MOR) is a systematic mathematical procedure to reduce the higher-order system(HOS). The reduced-order presents a replica of useful characteristics of the original system. The MOR have extensive application in computational physics, MEMS devices, chemical process, control systems, power systems, circuit designing. Numerous methods are advocated by researchers as per their thoughts and practical situations for solving the HOMs' in the frequency and time domain.

Traditional techniques follows systematic mathematical processes to reduced HOS. The Pade approximation is the old technique to reduce the HOS. It gives the reduced order but due to the mathematical uncertainty of the procedural steps, reduced-order may become unstable. The algorithm introduce in [1], equate the time-moment and uses the continued fraction synthesis to make reduced order stable if higher is stable. The computer -oriented algorithm uses the evaluateing the moment of impulse reponse using the MM in [2].A combination of its Markov paprameter and moments given in [3] . The instability occurs because of unpredictable matrix output in the case of the time MM in $[2,4]$ making the reduced-order stable. The unstable reduced model has to regain stability using the pole placement method in [5]. The SE used the pole-zero patterns to obtain the reduced order model(ROM) in [6] with the guarantee of stability in ROM. The other method Routh Approximation[7], the continued fraction method [8] and its inversion is used to obtain the ROM for preserving the stability. The result obtained from reduced-order has an error of approximation. The error of approximation is improved by combining the result of two methods termed the mixed method.

The mixed-method consists of two methods, one method to obtain the numerator parameter and the other method is used to obtain the denominator parameter of ROM. The continued fraction third form where the $s=0$ to inf is proposed in [9]. The problem of instability of ROM is solved using the combination of SE and modified Cauer continued fraction [10, 11]. Pade approximation using the Routh-Hurwitz array for stable reduction [12, 13]. Dominant Eigen-value concept with continued fraction approach $[14,15]$. Pade approximation using S.E. proposed by Chen et al in [16] and its improvement in [17]. Factor division with Routh Hurwitz array [18], Eigen spectrum analysis and Cauer Second from [19], Cauer application[20].Eigen spectrum and Pade approximation [21] factor division method with SE in [22]. Stability array with SE method in [23]. Differential equation method used to derive the denominator parameter .Routhain-array method for obtaining the numerator parametd[24] are used to obtain the ROM .

In recent times, nature-inspired techniques based on natural phenomena such as genes, swarm, physics and human behaviour based are being used for MOR. These all algorithms are used to minimize the approximation error 
(response indices especially Integral Square Error) which result out from traditional methods of frequency or time domain. The well-established approach in MOR is a genetic algorithm(G.A.) with Routh-approximation by Li et al. in [25] in which the denominator parameter of reduced-order is calculated by Routh approximation and numerator parameter is calculated by the time delay are identified by G.A.Particle swarm optimization by Z.W. Wang et-al in [26]. A trend is followed by researchers for the implementation of optimization techniques in the MOR field [27-43] to find the unknown ROM. The numerator or denominator parameter in case of mixed-method [44] or to minimize the error between the original system response and reduced system response concluding a new reduced order transfer function.

The MM techniques have been used with Markova parameters for mixed-method in [3, 45]. However, its failed analysis of MM with the SE method is in [46]. This manuscript makes an effort to propose a mixed method with using the MMT and SE with changes in the Routhain-array of the MM technique. The proposed mixed method is tested on the selected higher-order systems and the ROM step response characteristics and response indices error are compared to justify the result. The conclusion shows the effectiveness of the novel mixed method.

The paper is well-written and divided into six sections and their subsections. Starting from the Introduction which consists of the literature review, the second section is of followed by problem formulation, the third section is of Methodology chosen for mixed-method with subsection 3.1 for Moment Matching and 3.2 Stability Equation followed by the numerical examples and results with discussion with the last part of conclusion effectively shows the resulting outcome of the proposed methods.

\section{Problem Formulation}

Consider the LTI higher-order system in transfer function form given in Equation (1)

$$
G(\mathrm{~s})=\frac{N^{a}(\mathrm{~s})}{D^{b}(\mathrm{~s})}=\frac{\sum_{i=0}^{n-1} b_{i} s^{i}}{\sum_{i=0}^{n} a_{i} s^{i}}
$$

Here, $N^{a}(\mathrm{~s})$ and $D^{b}(\mathrm{~s})$ are the numerator and denominator polynomial of a higher-order system. The reducedorder system represented in Equation (2)

$$
R_{r}(\mathrm{~s})=\frac{N^{u}(\mathrm{~s})}{D^{u}(\mathrm{~s})}=\frac{\sum_{i=0}^{u-1} P_{i} s^{i}}{\sum_{i=0}^{u} Q_{i} s^{i}}
$$

In the above Equation (2) $N^{u}(\mathrm{~s})$ and $D^{u}(\mathrm{~s})$ are the unknown numerator and denominator parameter of the reduced-order system.

\section{Methodologies}

The moment matching and stability equation are used to develop the novel method. The moment matching method is used to determine the denominator parameter and the stability equation used to determine the numerator parameter of the ROM.

\subsection{Moment Matching}

The moment matching method is given in[2], according to the method consider a system having transfer function in the ratio of two polynomial

$$
G_{i j}(s)=\frac{b_{m} s^{m}+b_{m-1} s^{m-1}+\mathrm{L} \mathrm{L}+b_{1} s+b_{0} s^{0}}{a_{n} s^{n}+a_{n-1} s^{n-1}+\mathrm{L} \mathrm{L}+a_{1} s+a_{0} s^{0}},(m \leq n)
$$


The $G_{i j}(s)$ represents the original transfer function of the higher-order system which may also be represented as $G_{11}(s)$ or $G(s)$. The $b_{m}, b_{m-1} \mathrm{~L} \mathrm{~L} b_{1}, b_{0}$ are the numerator parameter and denominator parameter is represented by $a_{n}, a_{n-1}, \mathrm{~L} \mathrm{~L}, a_{1}, a_{0}$. The diminished order of $G_{i j, r}(s)$ is represented as in Equation (4)

$$
G_{i j, r}(s)=\frac{P_{0} s^{m_{r}-1}+P_{1} s^{m_{r}-2}+P_{2} s^{m_{r}-3}+\mathrm{L}+P_{m_{r}-1} s+P}{Q_{0} s^{n_{r}}+Q_{1} s^{n_{r}-1}+Q_{2} s^{n_{r}-2}+\mathrm{L}+Q_{n} s+Q}, \quad\left(m_{r} \leq n_{r}\right)
$$

The reduced-order numerator parameter is represented by $P_{0}, P_{1}, P_{2} \ldots \ldots$ and denominator parameter is represented as $Q, Q_{0}, Q_{1} \ldots \ldots \ldots \ldots .$. . The system is considered for time moment matching with the transfer function represented in Equation (5)

$$
G(s)=\int_{0}^{\infty} y_{\delta}(t) e^{-s t} d t
$$

$y_{\delta}(t)$ is the impulse response of $G(s)$. The power series expansion $e^{-s t}$ is written as in Equation (6)

$$
\begin{aligned}
G(s) & =\int_{0}^{\infty} y_{\delta}(t)\left\{1-s t+\frac{s^{2} t^{2}}{2 !}-\frac{s^{3} t^{3}}{3 !}+\mathrm{L}\right\} d t \\
& =\int_{0}^{\infty} y_{\delta}(t) d t-s \int_{0}^{\infty} t y_{\delta}(t) d t+s^{2} \int_{0}^{\infty} \frac{t^{2}}{2 !} y_{\delta}(t) d t-\mathrm{L} \\
G(s) & =c_{0}+c_{1} s+c_{2} s^{2}+\mathrm{L}
\end{aligned}
$$

Where coefficient $c_{i}$

$c_{i}=\frac{(-1)^{i}}{i !} \int_{0}^{\infty} t^{i} y_{\delta}(t) d t, \quad i=0,1,2,3 \mathrm{~L}$

The $\int_{0}^{\infty} t^{i} y_{\delta}(t) d t$ is the $i^{t h}$ moment of $y_{\delta}(t)$.

\subsection{Stability Equation}

The Stability Equation (SE) method is selected from the [6]. The traditional method gives the guarantee of stability of the reduced-order which is calculated as mentioned. Let the transfer function of a HOS given in Equation (3) be written as in Equation (9)

$$
G(s)=\frac{G_{N}(s)}{G_{D}(s)}=\frac{b_{n} \cdot s^{n}+b_{n-1} \cdot s^{n-1}+\mathrm{L} \mathrm{L}+b_{1} \cdot s+b_{0} s^{0}}{a_{m} \cdot s^{m}+a_{m-1} \cdot s^{m-1}+\mathrm{L} \mathrm{L}+a_{1} \cdot s+a_{0} s^{0}}
$$

Where $m \geq n, G_{N}(s)$ and $G_{D}(s)$ are the numerator and denominator of the $G(s)$. Splitting $G_{N}(s)$ and $G_{D}(s)$ into thir even and odd parts which is generally represented in Equation (10).

$$
G(s)=\frac{G_{N e}(s)+G_{N o}(s)}{G_{D e}(s)+G_{D o}(s)}
$$

Where,

$$
\left\{\begin{array}{l}
G_{N e}(s)=\sum_{i=0,2,4 . .}^{n} b_{i} s^{i} \\
G_{N o}(s)=\sum_{i=1,3,5 \ldots}^{n} b_{i} s^{i}
\end{array}\right.
$$

And 


$$
\left\{\begin{array}{l}
G_{D e}(s)=\sum_{i=0,2,4 . .}^{m} b_{i} s^{i} \\
G_{D o}(s)=\sum_{i=1,3,5 \ldots}^{m} b_{i} s^{i}
\end{array}\right.
$$

Equation (11) and Equation (12) are S.E. of the numerator $\left[G_{N}(s)\right]$ and the denominator $\left[G_{D}(s)\right]$, respectively. The roots of $G_{N e}$ and $G_{D e}$ are known as zeros $\left(z_{i}\right)$ and those of $G_{N o}$ and $G_{D o}$ are known as poles $\left(p_{i}\right)$. The poles and zeros obtained by the conventional method. Then, for a stable system Equation (11) and (12) can be factored as.

$$
\begin{aligned}
& \left\{\begin{array}{l}
G_{N e}(s)=\prod_{i=1}^{n^{\prime}}\left(s^{2}+z_{N i}^{2}\right) \\
G_{N o}(s)=s \prod_{i=1}^{n^{\prime}}\left(s^{2}+p_{N i}^{2}\right)
\end{array}\right. \\
& \left\{\begin{array}{l}
G_{D e}(s)=\prod_{i=1}^{m^{\prime}}\left(s^{2}+z_{N i}^{2}\right) \\
G_{D o}(s)=s \prod_{i=1}^{m^{\prime}}\left(s^{2}+p_{N i}^{2}\right)
\end{array}\right.
\end{aligned}
$$

Where,

$$
\begin{aligned}
m^{\prime}=\frac{m}{2} & \text { if } m \text { is even, } \\
& =\frac{(m-1)}{2} \quad \text { if } m \text { is odd; }
\end{aligned}
$$

$m^{\prime}=\frac{n}{2} \quad$ if $n$ is even,

$$
=\frac{(n-1)}{2} \text { if } n \text { is odd; }
$$

$p_{1}^{2}<p_{2}^{2}<p_{3}^{2} \ldots$, are poles and $z_{1}^{2}<z_{2}^{2}<z_{3}^{2} \ldots . \quad$. zeros having lesser magnitudes are more dominant with larger magnitudes, so, discarding the higher magnitude is a systematic method for dropping the order using S.E. The diminished models of the polynomial $G_{N}(s)$ and $G_{D}(s)$ can be built, and finally, the diminished model of $G(s)$ can be achieved. To make the steady-state answer of the ROM is identical to that of the original system. The reduced-order achieved using SE of $G_{N}(s)$ can be written as in Equation (16)

$$
\left\{\begin{array}{l}
G_{N e}^{\prime}(s)=z_{n}^{2} \prod_{i=1}^{n^{\prime}-1}\left(s^{2}+z_{i}^{2}\right) \\
G_{N o}^{\prime}(s)=s p_{n}^{2} \prod_{i=1}^{n^{\prime}-1}\left(s^{2}+p_{i}^{2}\right)
\end{array}\right.
$$

Then the reduced system represented as in Equation (17)

$$
F_{n-1}(s)=\frac{F_{N}^{\prime}(s)}{F_{D}^{\prime}(s)}=\frac{h_{12} s+h_{11}}{v_{23} s+v_{22} s+v_{21}}
$$

\subsection{Routhain Approach}

The moment matching has the Routhain array approach for obtaining a reduced order. This can be clarified from [2] and mentioning it as case-1 in our experiment analysis.

\subsubsection{Case-1}

The higher-order physical system may be represented in transfer function form as in Equation. (3). 
Here, $b_{m} s^{m}+b_{m-1} s^{m-1}+\mathrm{L} \mathrm{L}+b_{1} s+b_{0}$ are numerator parameter and $a_{n} s^{n}+a_{n-1} s^{n-1}+\mathrm{L} \mathrm{L}+a_{1} s+a_{0}$ is the denominator parameter of the higher-order system. Divide the higher-order transfer function $a_{0}$ to make it unity.

$G_{i j}(s)=\frac{b_{m} s^{m} / a_{0}+{ }^{b_{m-1}} s^{m-1} / a_{0}+\mathrm{L} \mathrm{L}+b_{1} s / a_{0}+b_{0} / a_{0}}{a_{n} s^{n} / a_{0}+{ }^{a_{n-1}} s^{n-1} / a_{0}+\mathrm{L} \mathrm{L}+{ }_{1} s / a_{0}+a_{0} / a_{0}},(m \leq n)$

The new coefficient of " $s$ " is formed as $b_{m} s^{m} / a_{0}=B_{m}, b_{m-1} s^{m-1} / a_{0}=B_{m-1}, \mathrm{~L} b_{0} / a_{0}=B_{0}$ for the numerator and $a_{n} s^{n} / a_{0}=A_{n}, b_{n-1} s^{n-1} / a_{0}=A_{n-1}, \mathrm{~L} / a_{0} / a_{0}=1$ for denominator parameters. Equation (3) changes as Equation (19)

$$
G_{i j}(s)=\frac{B_{m} s^{m}+B_{m-1} s^{m-1}+\mathrm{L} \mathrm{L}+B_{1} s+B_{0} s^{0}}{A_{n} s^{n}+A_{n-1} s^{n-1}+\mathrm{L} \mathrm{L}+A_{1} s+1},(m \leq n)
$$

The denominator $1, A_{1}, A_{2}, \mathrm{~L}$ and numerator $B_{0}, B_{1}, B_{2, \mathrm{~L}}$ parameter are used to create the routhain array as mentioned in Table 1.

Table 1: Routhain Table for Time Moment Matching

\begin{tabular}{|c|c|c|c|c|}
\hline & 1 & $A_{1}=\frac{a_{1}}{a_{0}}$ & $A_{2}=\frac{a_{2}}{a_{0}}$ & $\mathrm{~L}$ \\
\hline$c_{0}$ & $B_{0}=\frac{b_{0}}{a_{0}}$ & $B_{1}=\frac{b_{1}}{a_{0}}$ & $\mathrm{~L}$ & \\
\hline$c_{1}$ & $C_{1}=\left(\left(1 \times B_{1}\right)-B_{0} \times A_{1}\right)$ & & & \\
\hline$c_{2}$ & & & & \\
\hline $\mathrm{N}$ & & & & \\
\hline
\end{tabular}

The routhain parameter used to find the lower order using [2]the following matrix Equation. (20).

$\left[\begin{array}{c}c_{0} \\ c_{1} \\ c_{2} \\ \mathrm{M} \\ c_{m} \\ \mathrm{~K} \\ c_{m+1} \\ c_{m+2} \\ \mathrm{M} \\ c_{m+n}\end{array}\right]=\left[\begin{array}{cccccccccc}0 & 0 & \mathrm{~K} & 0 & 0 & \mathrm{M} & 0 & 0 & 0 & 0 \\ -c_{0} & 0 & \mathrm{~K} & 0 & 0 & \mathrm{M} & 0 & 0 & 0 & 0 \\ -c_{1} & -c_{0} & \mathrm{~K} & 0 & 0 & \mathrm{M} & 0 & 0 & 0 & 0 \\ \mathrm{M} & \mathrm{M} & \mathrm{M} & \mathrm{M} & \mathrm{M} & \mathrm{M} & \mathrm{M} & \mathrm{M} & \mathrm{M} & \mathrm{M} \\ -c_{m-1} & -c_{m-2} & \mathrm{~K} & -c_{0} & 0 & \mathrm{M} & 0 & 0 & 0 & 0 \\ \mathrm{~K} & \mathrm{~K} & \mathrm{~K} & \mathrm{~K} & \mathrm{~K} & \mathrm{~K} & \mathrm{~K} & \mathrm{~K} & \mathrm{~K} & \mathrm{~K} \\ -c_{m} & -c_{m-1} & \mathrm{~K} & -c_{1} & -c_{0} & \mathrm{M} & \mathrm{L} & \mathrm{L} & \mathrm{L} & 0 \\ -c_{m+1} & -c_{m} & \mathrm{~K} & & -c_{1} & \mathrm{M} & -c_{0} & \mathrm{~L} & \mathrm{~L} & 0 \\ & & \mathrm{~K} & & & \mathrm{M} & \mathrm{L} & -c_{0} & 0 & 0 \\ -c_{m+n-1} & -c_{m+n-2} & \mathrm{~K} & & & \mathrm{M} & \mathrm{L} & -c_{1} & -c_{0} & 0\end{array}\right]\left[\begin{array}{c}c_{21} \\ c_{31} \\ c_{41} \\ \mathrm{M} \\ c_{n .1} \\ \mathrm{~K} \\ 0 \\ 0 \\ 0 \\ 0\end{array}\right]+\left[\begin{array}{c}c_{31} \\ c_{33} \\ c_{43} \\ \mathrm{M} \\ c_{2, m+1} \\ \mathrm{~K} \\ 0 \\ 0 \\ 0 \\ 0\end{array}\right]$

The $c_{11}, c_{12}, c_{21}$ and $c_{22}$ represents the upper left hand, upper right hand lower left hand and lower right-hand submatrices of the coefficient matrix. The reduced second order from the above Equation (21) is given by

$$
\begin{aligned}
& \hat{a}_{1}=C_{21}^{-1} \hat{c}_{2}=\left[\begin{array}{rr}
-c_{1} & -c_{0} \\
-c_{2} & -c_{1}
\end{array}\right]^{-1} \times\left[\begin{array}{l}
c_{2} \\
c_{3}
\end{array}\right]=\left[\begin{array}{l}
u_{12} \\
u_{13}
\end{array}\right] \\
& \hat{a}_{2}=\hat{c}_{1}-C_{11} \hat{a}_{1}=\left[\begin{array}{rr}
0 & 0 \\
-c_{0} & 0
\end{array}\right] \times\left[\begin{array}{l}
u_{12} \\
u_{13}
\end{array}\right]=\left[\begin{array}{l}
u_{21} \\
u_{22}
\end{array}\right]
\end{aligned}
$$


Above Equation. (21) gives the numerator and Equation (22) gives the denominator part of the reduced secondorder and represented as in Equation. (23):

$$
R_{1}(\mathrm{~s})=\frac{u_{21}+u_{22} s}{1+u_{12} s+u_{13} s^{2}}
$$

\subsubsection{Case-2 Proposed approach}

In the experimental case, we reduced-order obtained the following steps as given in Equation (24) supposing that

$$
G_{i j}(s)=\frac{b_{m} s^{m} / a_{n} s^{n}+b_{m-1} s^{m-1} / a_{n} s^{n}+\mathrm{L} \mathrm{L}+b_{1} s / a_{n} s^{n}+b_{0} / a_{n} s^{n}}{a_{n} s^{n} / a_{n} s^{n}+a_{n-1} s^{n-1} / a_{n} s^{n}+\mathrm{L} \mathrm{L}+{ }^{a_{1} s} / a_{n} s^{n}+a_{0} / a_{n} s^{n}},(m \leq n)
$$

The new coefficient of " $s$ " is formed as $b_{m} s^{m} / a_{n} s^{n}=E_{m}, b_{m-1} s^{m-1} / a_{n} s^{n}=E_{m-1}, \mathrm{~L} \mathrm{~L}, b_{1} s / a_{n} s^{n}=E_{1}$ and ,$b_{0} / a_{n} s^{n}=E_{0}$ for the numerator and $a_{n} s^{n} / a_{n} s^{n}=1, a_{n-1} s^{n-1} / a_{n} s^{n}=F_{n-1}, \mathrm{~L} \mathrm{~L}, a_{1} s / a_{n} s^{n}=F_{1}, a_{0} / a_{n} s^{n}=F_{0}$ for the denominator parameter. The new transfer function form as in Equation (25)

$$
R_{2 i j}(s)=\frac{E_{m}+E_{m-1} s^{m-1}+\mathrm{L} \mathrm{L}+E_{1} s+E_{0} s^{0}}{1+F_{n-1} s^{n-1}+\mathrm{L} \mathrm{L}+F_{1} s+F_{0} s^{0}},(m \leq n)
$$

The coefficient's of "s" denominator and numerator put in routhain array as mentioned in Table 2

Table 2:Routhain Array for Moment Matching

The

\begin{tabular}{|c|c|c|c|c|}
\hline & 1 & $F_{n-1}=\frac{a_{n-1} s^{n-1}}{a_{n} s^{n}}$ & $F_{n-2}=\frac{a_{n-2} s^{n-1}}{a_{n} s^{n}}$ & \\
\hline$c_{0}$ & $E_{m}=\frac{b_{m} s^{m}}{a_{n} s^{n}}$ & $E_{m-1}=\frac{b_{m-1} s^{m-1}}{a_{n} s^{n}}$ & $\mathrm{~L}$ & \\
\hline$c_{1}$ & $C_{1}=\left(1 \times E_{m-1}-E_{m} \times F_{n-1}\right)$ & & & \\
\hline$c_{2}$ & & & & \\
\hline $\mathrm{N}$ & & & & \\
\hline
\end{tabular}

value of $c_{0}, c_{1}, c_{2}, c_{3}, \mathrm{~K} \mathrm{~K}, c_{n}$ is obtained from Table 1 and Table 2 different in both cases.

The steps from Equation (20) to Equation (22) are repeated and a new reduced order formed using the MMT as given in Equation (26)

$$
R_{2}(\mathrm{~s})=\frac{e_{21}+e_{22} s}{1+f_{12} s+f_{13} s^{2}}
$$

The experimental transfer function from Equation (25) is reduced and reduced order using the stability equation mentioned in Equation (27)

$$
R_{3}(\mathrm{~s})=\frac{l_{21}+l_{22} s}{1+k_{12} s+k_{13} s^{2}}
$$

\section{Proposed Mixed-Mixed Method}

The numerator parameter of Equation (24) and denominator parameter in Equation (17) are mixed in order to create a mixed method given in Equation (28)

$$
R_{M S}(s)=\frac{u_{21}+u_{22 s}}{v_{23} s+v_{22} s+v_{21}}
$$


The mixed-method in Equation (28) is not resulted in satisfactory using the MM and SE. Therefore, experimental case 2 is implemented. The reduced-order numerator parameter used from the SE from Equation (17) and denominator parameter from the reduced moment matching in transfer function Equation (27), resulted in mixedmethod mentioned in Equation (29)

$$
R_{S M}(s)=\frac{h_{12} s+h_{11}}{u_{13} s^{2}+u_{22} s+1}
$$

The proposed mixed-method approach is justified using the implementation of a higher-order system as mentioned in section 5.

\section{Implementation and Result analysis}

The method is applied on the LTI SISO system given as Example 1 and Example 2

5.1. Example 1: . Consider a sixth-order system from [39] as mentioned in transfer function format given in Equation (30)

$$
G(s)=\frac{2 s^{5}+3 s^{4}+16 s^{3}+20 s^{2}+8 s+1}{2 s^{6}+33.6 s^{5}+155.94 s^{4}+209.46 s^{3}+102.42 s^{2}+18.3 s+1}
$$

The higher-order mentioned in Equation (30) is reduced according to the steps from Equation (19-25). The routhain array for obtaining the reduced-order given in Table 3

Table 3: Routhain Array with Case-1

\begin{tabular}{|l|l|l|l|l|l|l|l|}
\hline & $\mathbf{1}$ & $\mathbf{1 8 . 3}$ & $\mathbf{1 0 2 . 4 2}$ & $\mathbf{2 0 9 . 4 6}$ & $\mathbf{1 5 5 . 9 4}$ & $\mathbf{3 3 . 6}$ & $\mathbf{2}$ \\
\hline$c_{0}=1$ & $\mathbf{1}$ & $\mathbf{8}$ & $\mathbf{2 0}$ & $\mathbf{1 6}$ & $\mathbf{3}$ & $\mathbf{2}$ & $\mathbf{0}$ \\
\hline$c_{1}=-10.3$ & -10.3 & -82.42 & -193.46 & -152.94 & -31.6 & -2 & 0 \\
\hline$c_{2}=106.07$ & 106.07 & 861.466 & 2004.498 & 1574.582 & 344.08 & 20.6 & \\
\hline$c_{3}=-1079.62$ & -1079.62 & -8859.19 & -20642.8 & -16196.5 & -3543.35 & & \\
\hline & 10897.76 & 89931.33 & 209939.7 & 164811.8 & & & \\
\hline & -109498 & -906209 & -2117834 & & & & \\
\hline & 1097599 & 9096925 & & & & & \\
\hline & $-1.1 \mathrm{E}+07$ & & & & & & \\
\hline
\end{tabular}

The denominator and numerator coefficient of ROM are obtained in Equation (32) and Equation (31) respectively

$$
\begin{aligned}
\hat{a}_{1}=C_{21}^{-1} \hat{c}_{2}=\left[\begin{array}{ll}
-c_{1} & -c_{0} \\
-c_{2} & -c_{1}
\end{array}\right]^{-1} \times\left[\begin{array}{l}
c_{2} \\
c_{3}
\end{array}\right]=\left[\begin{array}{l}
a_{12} \\
a_{13}
\end{array}\right] \\
=\left[\begin{array}{cc}
-(-10.3) & -(1) \\
-(106.07) & -(-10.3)
\end{array}\right]^{-1} \times\left[\begin{array}{c}
106.07 \\
-1079.62
\end{array}\right] \\
=1.0 e+03\left[\begin{array}{cc}
0.5150 & 0.0500 \\
5.3035 & 0.5150
\end{array}\right] \times\left[\begin{array}{c}
106.07 \\
-1079.62
\end{array}\right]=1.0 e+03\left[\begin{array}{l}
0.6450 \\
6.5379
\end{array}\right]=\left[\begin{array}{c}
645 \\
6537.9
\end{array}\right] \\
\hat{a}_{2}=\hat{c}_{1}-C_{11} \hat{a}_{1}=\left[\begin{array}{l}
c_{0} \\
c_{1}
\end{array}\right]-\left[\begin{array}{cc}
0 & 0 \\
-c_{0} & 0
\end{array}\right] \times\left[\begin{array}{l}
a_{12} \\
a_{13}
\end{array}\right]=\left[\begin{array}{c}
a_{21} \\
a_{22}
\end{array}\right] \\
=\left[\begin{array}{c}
1 \\
-10.3
\end{array}\right]-\left[\begin{array}{cc}
0 & 0 \\
-1 & 0
\end{array}\right] \times\left[\begin{array}{c}
645 \\
6537.9
\end{array}\right]=\left[\begin{array}{c}
1.0000 \\
634.7500
\end{array}\right]
\end{aligned}
$$

The reduced order using the MM case-1 is given in Equation (33)

$$
R_{1}(s)=\frac{634.75 s+1}{6537.9 s^{2}+645 s+1}
$$

The ROM using S.E. is given in Equation (34) 


$$
R_{2}(s)=\frac{8 s+1}{102.42 s^{2}+18.3 s+1}
$$

The reduced mixed method using the MM and SE as mentioned in Equation (30) given in Equation (35)

$$
R_{1}(s)=\frac{634.75 s+1}{102.42 s^{2}+18.3 s+1}
$$

The step response characteristics of the Mixed method not follows the original system and reduced Therefore the experimental case-2 is applied to the original system in Equation (31) to obtain a well-mixed method.

Table 4:Routhain array Case-2

\begin{tabular}{|l|l|l|l|l|l|l|l|}
\hline & $\mathbf{1}$ & $\mathbf{1 6 . 8}$ & $\mathbf{7 7 . 9 7}$ & $\mathbf{1 0 4 . 7 3}$ & $\mathbf{5 1 . 2 1}$ & $\mathbf{9 . 1 5}$ & $\mathbf{0 . 0 5}$ \\
\hline$c_{0}=1$ & $\mathbf{1}$ & $\mathbf{1 . 5}$ & $\mathbf{8}$ & $\mathbf{1 0}$ & $\mathbf{4}$ & $\mathbf{0 . 5}$ & \\
\hline$c_{1}=-15.3$ & -15.3 & -69.97 & -94.73 & -47.21 & -8.65 & & \\
\hline$c_{2}=187.07$ & 187.07 & 1098.211 & 1555.159 & 774.863 & & & \\
\hline$c_{3}=-2044.57$ & -2044.57 & -13030.7 & -18817 & & & & \\
\hline$c_{4}=21318$ & 21318 & 140597.8 & & & & & \\
\hline & -217545 & & & & & & \\
\hline
\end{tabular}

Reduced-Order Modelling with case-2 follows the steps from Equation (26,27), Routhain Table 2 and from Equation (18-23).

$$
\begin{aligned}
& G(s)=\frac{2 s^{5}+3 s^{4}+16 s^{3}+20 s^{2}+8 s+1}{2 s^{6}+33.6 s^{5}+155.94 s^{4}+209.46 s^{3}+102.42 s^{2}+18.3 s+1} \\
& =\frac{s^{5}+1.5 s^{4}+8 s^{3}+10 s^{2}+4 s+0.5}{s^{6}+16.8 s^{5}+77.97 s^{4}+104.73 s^{3}+51.21 s^{2}+9.15 s+0.5} \\
& \hat{a}_{1}=C_{21}^{-1} \hat{c}_{2}=\left[\begin{array}{ll}
-c_{1} & -c_{0} \\
-c_{2} & -c_{1}
\end{array}\right]^{-1} \times\left[\begin{array}{l}
c_{2} \\
c_{3}
\end{array}\right]=\left[\begin{array}{l}
a_{12} \\
a_{13}
\end{array}\right]=\left[\begin{array}{cc}
-(-15.3) & -(1) \\
-(187.07) & -(-15.3)
\end{array}\right]^{-1} \times\left[\begin{array}{c}
187.07 \\
-2044.57
\end{array}\right] \\
& =\left[\begin{array}{ll}
0.3254 & 0.0213 \\
3.9785 & 0.3254
\end{array}\right] \times\left[\begin{array}{c}
187.07 \\
-2044.57
\end{array}\right]=\left[\begin{array}{l}
17.3884 \\
78.9720
\end{array}\right]
\end{aligned}
$$

Equation (39) gives the reduced order denominator parameter of MM with experimental case-2

$$
\begin{aligned}
\hat{a}_{2}=\hat{c}_{1}-C_{11} \hat{a}_{1}=\left[\begin{array}{l}
c_{0} \\
c_{1}
\end{array}\right]-\left[\begin{array}{cc}
0 & 0 \\
-c_{0} & 0
\end{array}\right] \times\left[\begin{array}{l}
a_{12} \\
a_{13}
\end{array}\right]=\left[\begin{array}{l}
a_{21} \\
a_{22}
\end{array}\right] \\
=\left[\begin{array}{c}
1 \\
-15.3
\end{array}\right]-\left[\begin{array}{cc}
0 & 0 \\
-1 & 0
\end{array}\right] \times\left[\begin{array}{l}
17.3884 \\
78.9720
\end{array}\right]=\left[\begin{array}{l}
1.0000 \\
2.0884
\end{array}\right]
\end{aligned}
$$

Equation (38) gives the numerator parameter and denominator parameter in Equation (37) of the MM with experimental case-2. The obtained reduced order represented in Equation (39)

$$
R_{11}(s)=\frac{2.0884 s+1}{78.9720 s^{2}+17.3884 s+1}
$$

The obtained reduced order of experimental case-2 is given in Equation (40)

$$
R_{22}(s)=\frac{4 s+0.5}{51.21 s^{2}+9.15 s+0.5}
$$

The proposed reduced-order follows using the SE and MM is given in Equation (43). The reduced-order follows the step response of the original system approximately

$$
R_{22}(s)=\frac{8 s+1}{78.9720 s^{2}+17.3884 s+1}
$$


The obtained reduced order from case- 1 and using case- 2 all are compared in the table and compared with the proposed mixed method. The obtained reduced order of HOS as in Equation (32) from case -1 and case-2 are given in step response characteristics in Figure 1.

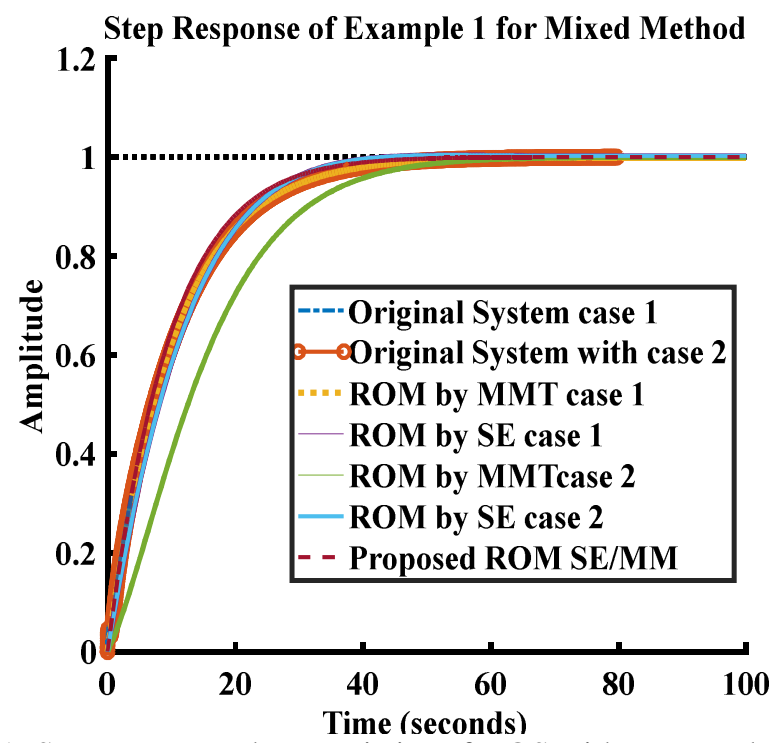

Figure 1: Step response characteristics of HOS with proposed reduced system

The reponse characteritics of the system is given in Table 5 along with the reduced order. The ST min, ST max and peak is approximately same as that of the original system

Table 5:Step response characteristics of obtained reduced order from Case-1, Case-2 and mixed methods with proposed mixed method

\begin{tabular}{|c|c|c|c|c|c|c|}
\hline \multirow[t]{2}{*}{ Reduced Order } & \multicolumn{6}{|c|}{ Step reponse characteristics } \\
\hline & RT & ST & $\begin{array}{l}\text { ST } \\
\min \end{array}$ & ST amx & Peak & PT \\
\hline HOS Eq. (32) & 22.7109 & 40.0475 & 0.9001 & 0.9994 & 0.9994 & 75.4235 \\
\hline Eq.(38) & 22.7109 & 40.0475 & 0.9001 & 0.9994 & 0.9994 & 75.4235 \\
\hline Eq. (35) & 22.6239 & 40.2598 & 0.9001 & 1.0000 & 1.0000 & 108.6304 \\
\hline Eq. (36) & 21.7088 & 33.7630 & 0.9020 & 1.0036 & 1.0036 & 53.6096 \\
\hline Eq. (41) & 28.3754 & 47.3095 & 0.9007 & 0.9991 & 0.9991 & 74.8759 \\
\hline Eq. (42) & 21.7088 & 33.7630 & 0.9020 & 1.0036 & 1.0036 & 53.6096 \\
\hline$R(s)=\frac{634.75 s+1}{102.42 s^{2}+18.3 s+1}$ & 0.1351 & 58.6403 & 0.9690 & 24.9314 & 024.9314 & 10.8250 \\
\hline$R(s)=\frac{8 s+1}{6537.9 s^{2}+645 s+1}$ & $1.3945 \mathrm{e}+03$ & $2.4853 \mathrm{e}+03$ & 0.9041 & 1.000 & 1.000 & $6.6934 \mathrm{e}+03$ \\
\hline$R(s)=\frac{2.0884 s+1}{51.21 s^{2}+9.15 s+0.5}$ & 28.8871 & 45.6568 & 1.8023 & 2.0027 & 2.0027 & 71.6513 \\
\hline$R(s)=\frac{4 s+0.5}{78.9720 s^{2}+17.3884 s+1}$ & 20.3957 & 35.1523 & 0.4518 & 0.4999 & 0.4999 & 66.5099 \\
\hline$R(s)=\frac{8 s+1}{78.9720 s^{2}+17.3884 s+1}$ & 20.3957 & 35.1523 & 0.9036 & 0.9997 & 0.9997 & 66.5099 \\
\hline
\end{tabular}



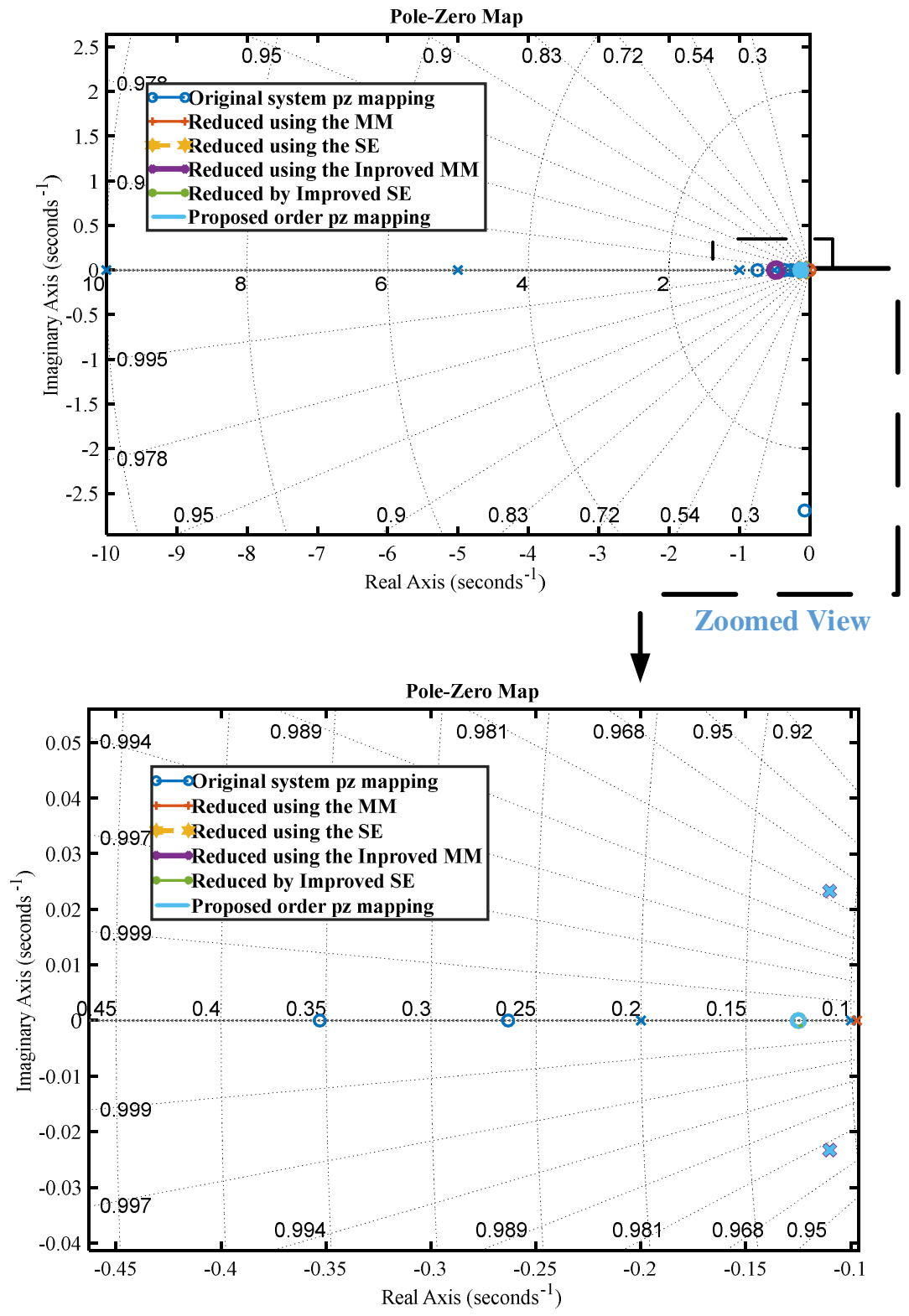

Figure 2: Pole zero mapping of the original system, reduced order using MM and SE, improved reduced order using MM and SE, proposed reduced order.

The selection of the proposed reduced order obtained from the MM in traditional format and with SE is represented in the pole -zero plot in Figure 2. The pole of the higher order are $-10,-5,-1,-0.5,-0.2,-0.1$ and zeros are $0.0711+2.6929 \mathrm{i},-0.0711-2.6929 \mathrm{i},-0.7415+0 \mathrm{i},-0.3530+0 \mathrm{i},-0.3530+0 \mathrm{i},-0.2632+0.0 \mathrm{i}$, reduced second order using the MM poles are $-0.9711,-0.0061$ and zero are -0.0016 , second order using SE is $-0.0893+0.0422 \mathrm{i},-0.0893-$ 0.0422 iand zeros are -0.1250 and the proposed second order using the SE and MM have poles $-0.1101+0.0233$; $-0.1101-0.233 \mathrm{i}$, zeros are -0.1250 . The pole of improved MMT is $-0.1101+0.0233 \mathrm{i},-0.1101-0.0233 \mathrm{i}$ and zero is 0.4788 and SE is $-0.0893+0.0422 \mathrm{i},-0.0893-0.0422 \mathrm{i}$ and -0.1250 . The pole zero placement of the proposed and higher order is clearly given in Figure 2 shows that the proposed order retains stability and its step response characteristics shows that response is similar to HOS. Table 5 concludes that the proposed reduced-order approximately replicates the original higher-order system. The justification of the reduced order is verified by comparing it with the reduced order available in the literature. Figure 3 shows the step reponse comparison of the proposed and reduced order available in the literature. 


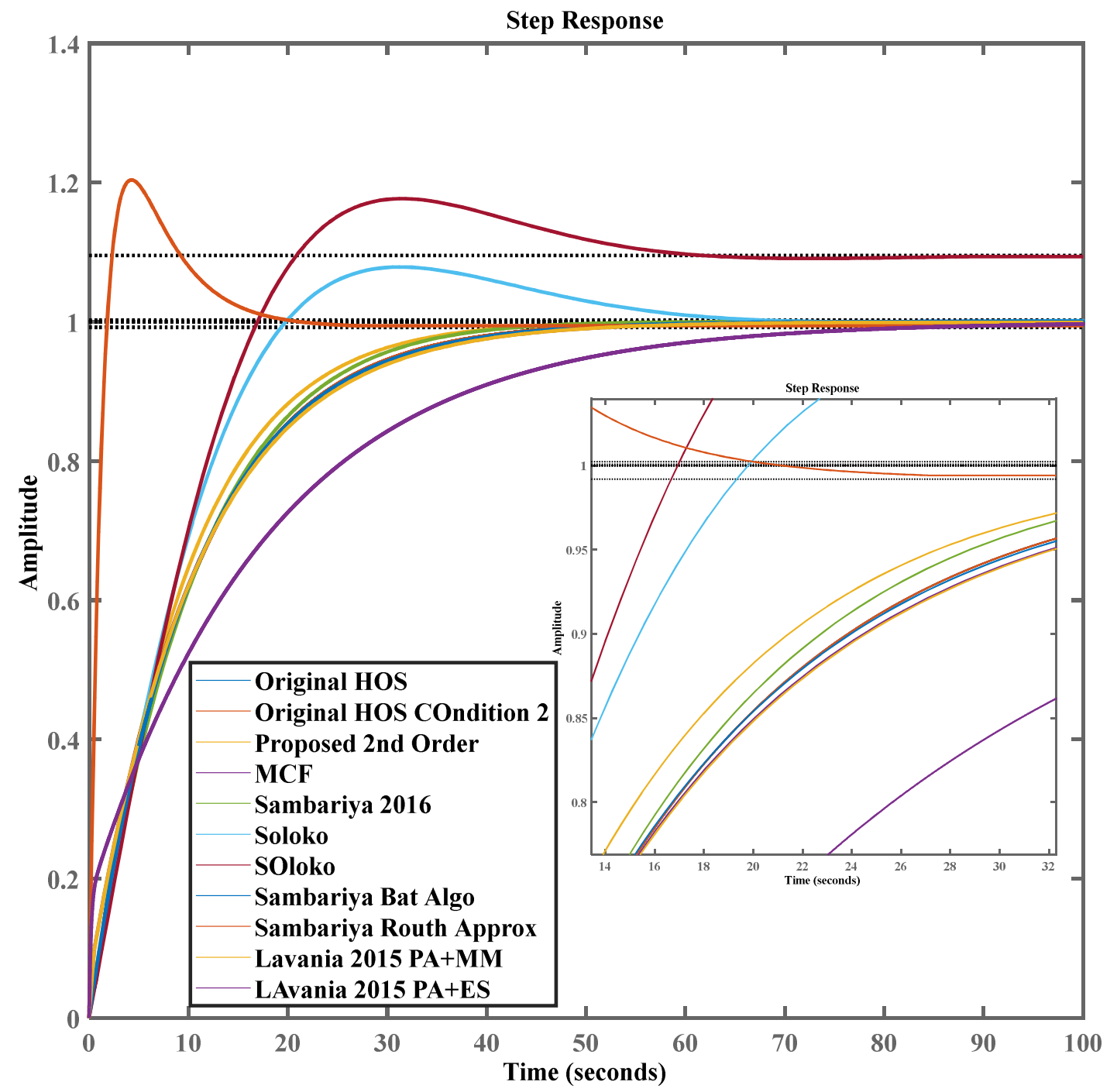

Figure 3: Step response characteristics of Novelty Condition 1 (SE) with condition 2(MM) (SE/MM)

Table 6: Comparative Step response characteristics of the Original system with proposed and equivalent systems from the literature

\begin{tabular}{|c|c|c|c|c|c|c|c|}
\hline \multirow[t]{2}{*}{ Reference } & \multirow[t]{2}{*}{ Reduced-order } & \multicolumn{6}{|c|}{ Step response characteristics } \\
\hline & & RT & ST & $\begin{array}{l}\text { ST } \\
\text { min }\end{array}$ & $\begin{array}{l}\text { ST } \\
\text { max }\end{array}$ & Peak & PT \\
\hline Original & Eq. (32) & $\begin{array}{l}22.710 \\
9\end{array}$ & $\begin{array}{l}40.047 \\
5\end{array}$ & $\begin{array}{l}0.900 \\
1\end{array}$ & 0.9994 & $\begin{array}{l}0.999 \\
4\end{array}$ & 75.4235 \\
\hline Proposed & $\frac{8 s+1}{78.9720 s^{2}+17.3884 s+1}$ & $\begin{array}{l}20.395 \\
7\end{array}$ & $\begin{array}{l}35.152 \\
3\end{array}$ & $\begin{array}{l}0.903 \\
6\end{array}$ & 0.9997 & $\begin{array}{l}0.999 \\
7\end{array}$ & 66.5099 \\
\hline $\mathrm{MCF}$ & $\frac{s+1.53725}{s^{2}+16.8373 s+1.53725}$ & $\begin{array}{l}23.935 \\
8\end{array}$ & $\begin{array}{l}42.005 \\
7\end{array}$ & $\begin{array}{l}0.901 \\
0\end{array}$ & $\begin{array}{l}0.9991 \\
0\end{array}$ & $\begin{array}{l}0.999 \\
0\end{array}$ & 74.7456 \\
\hline
\end{tabular}




\begin{tabular}{|c|c|c|c|c|c|c|c|}
\hline $\begin{array}{l}\text { Sambariya [47]; } \\
2016\end{array}$ & $\frac{0.0910 s+0.0109}{s^{2}+0.2012 s+0.01099}$ & $\begin{array}{l}21.594 \\
7\end{array}$ & $\begin{array}{l}36.245 \\
8\end{array}$ & $\begin{array}{l}0.901 \\
6\end{array}$ & 1.0001 & $\begin{array}{l}1.000 \\
1\end{array}$ & 68.2078 \\
\hline $\begin{array}{l}\text { Soloklo[39];201 } \\
\text { 4; MOHSA }\end{array}$ & $\frac{7.80016 s+0.81849}{87.58712 s^{2}+12.43314 s+0.8165}$ & $\begin{array}{l}14.299 \\
7\end{array}$ & $\begin{array}{l}52.986 \\
0\end{array}$ & $\begin{array}{l}0.905 \\
7\end{array}$ & 1.0787 & $\begin{array}{l}1.078 \\
7\end{array}$ & 31.1441 \\
\hline $\begin{array}{l}\text { Soloklo[39];201 } \\
\text { 4; Typical R-PA }\end{array}$ & $\frac{6.87815 s+1.09228}{89.54625 s^{2}+12.96860 s+0.9973}$ & $\begin{array}{l}15.057 \\
4\end{array}$ & $\begin{array}{l}50.376 \\
1\end{array}$ & $\begin{array}{l}0.987 \\
7\end{array}$ & 1.1769 & $\begin{array}{l}1.176 \\
9\end{array}$ & 31.1621 \\
\hline $\begin{array}{l}\text { Sambariya [48]; } \\
\text { Bat Algo. }\end{array}$ & $\frac{2.0950 s+1.3677}{20.0736 s^{2}+16.2644 s+1.3667}$ & $\begin{array}{l}22.993 \\
9\end{array}$ & $\begin{array}{l}40.931 \\
6\end{array}$ & $\begin{array}{l}0.902 \\
1\end{array}$ & 1.0007 & $\begin{array}{l}1.000 \\
7\end{array}$ & $\begin{array}{l}115.587 \\
9\end{array}$ \\
\hline $\begin{array}{l}\text { Sambariya }[24] ; \\
\text { Routh array }\end{array}$ & $\frac{2535.69 s+357.14}{2458.08 s^{2}+2196 s+360}$ & 1.3335 & $\begin{array}{l}16.976 \\
0\end{array}$ & $\begin{array}{l}0.913 \\
4\end{array}$ & 1.2037 & $\begin{array}{l}1.203 \\
7\end{array}$ & 4.2170 \\
\hline $\begin{array}{l}\text { Lavania[49]; } \\
\text { PA+MM }\end{array}$ & $\frac{s+1.53}{s^{2}+16.83 s+1.53}$ & $\begin{array}{l}24.039 \\
3\end{array}$ & $\begin{array}{l}42.186 \\
8\end{array}$ & $\begin{array}{l}0.901 \\
0\end{array}$ & 0.9990 & $\begin{array}{l}0.999 \\
0\end{array}$ & 75.0688 \\
\hline $\begin{array}{l}\text { Lavania[50]; } \\
\text { PA+ES }\end{array}$ & $\frac{s+0.307}{s^{2}+5.599 s+0.307}$ & $\begin{array}{l}38.026 \\
3\end{array}$ & $\begin{array}{l}67.230 \\
2\end{array}$ & $\begin{array}{l}0.900 \\
1\end{array}$ & 0.9981 & $\begin{array}{l}0.998 \\
1\end{array}$ & $\begin{array}{l}109.637 \\
8\end{array}$ \\
\hline
\end{tabular}

In Table 6 it is clear that the proposed reduced-order system has the approximately same response as that of the original system and competitively competes with the response from literature. To justify the response of the proposed reduced order of the randomly chosen higher-order system from the literature have a minimum error between them so, the calculation of Integral time absolute error (ITAE), Integral absolute error (IAE) and Integral square error (ISE) is calculated and compared in Table 7. The response indices, i.e Integral Square Error (ISE) penalizes the larger errors more than the smaller error. This gives a more conservative response and the reduced system return faster to the set point. Integral Absolute Error (IAE) essentially takes the absolute value of the error. The negative area is accounted for when the IAE is used and diminishing the problem encountered with Integral error and Integral Time Absolute Error (ITAE) is the absolute value of error multiplied by the time, this results in error existing overtime being penalized even they may be small and result in more heavy damped response and these errors are given as

Integral Square Error (ISE) is given in Eq. (42)

$$
I S E=\int_{0}^{\infty}\left[G(t)-G_{r}(t)\right]^{2} d t
$$

Integral Absolute Error (IAE) is given in Eq. (43)

$$
I A E=\int_{0}^{\infty}\left|G(t)-G_{r}(t)\right| d t
$$

Integral Time Absolute Error (ITAE) is given in Eq. (44)

$$
\text { ITAE }=\int_{0}^{\infty} t \cdot\left|G(t)-G_{r}(t)\right| d t
$$

\begin{tabular}{|c|c|c|c|c|}
\hline \multirow[t]{2}{*}{ Reference } & \multirow[t]{2}{*}{ Reduced -Order } & \multicolumn{3}{|c|}{ Response Indices Error } \\
\hline & & ITAE & IAE & ISE \\
\hline Proposed & $\frac{8 s+1}{78.9720 s^{2}+17.3884 s+1}$ & 0.7852 & 0.1151 & 0.00226 \\
\hline
\end{tabular}

In response indices, Eq. $G(t)$ is the step response of the higher-order and $G_{r}(t)$ is the response of the lower order.

Table 7: Comparative Response Indices of Proposed and from Literature 


\begin{tabular}{|l|l|l|l|l|}
\hline MCF & $\frac{s+1.53725}{s^{2}+16.8373 s+1.53725}$ & 0.6773 & 0.1707 & 0.005015 \\
\hline $\begin{array}{l}\text { Sambariya [47]; } \\
2016\end{array}$ & $\frac{0.0910 s+0.0109}{s^{2}+0.2012 s+0.01099}$ & 0.6824 & 0.1291 & 0.002222 \\
\hline $\begin{array}{l}\text { Soloklo[39];2014; } \\
\text { MOHSA }\end{array}$ & $\frac{7.80016 s+0.81849}{87.58712 s^{2}+12.43314 s+0.81657}$ & 1.34 & 0.1853 & 0.5377 \\
\hline $\begin{array}{l}\text { Soloklo[39];2014; } \\
\text { Typical R-PA }\end{array}$ & $\frac{6.87815 s+1.09228}{89.54625 s^{2}+12.96860 s+0.99732}$ & 1.365 & 0.221 & 2.8887 \\
\hline $\begin{array}{l}\text { Sambariya [48]; } \\
\text { Bat Algo. }\end{array}$ & $\frac{2.0950 s+1.3677}{20.0736 s^{2}+16.2644 s+1.3667}$ & 3.2244 & 0.03557 & $4.85 \mathrm{e}-04$ \\
\hline $\begin{array}{l}\text { Sambariya [24]; } \\
\text { Routh array }\end{array}$ & $\frac{2535.69 s+357.14}{2458.08 s^{2}+2196 s+360}$ & 34.94 & 6.376 & 4.812 \\
\hline $\begin{array}{l}\text { Lavania[49]; } \\
\text { PA+MM }\end{array}$ & $\frac{s+1.53}{s^{2}+16.83 s+1.53}$ & 0.6202 & 0.1621 & 0.0397 \\
\hline $\begin{array}{l}\text { Lavania[50]; } \\
\text { PA+ES }\end{array}$ & $\frac{s+0.307}{s^{2}+5.599 s+0.307}$ & 2.556 & 0.5108 & 0.0063 \\
\hline
\end{tabular}

5.2. Example 2: The fourth order system considered from [43] , represented in Equation (45)

$G(s)=\frac{s^{3}+7 s^{2}+24 s+24}{s^{4}+10 s^{3}+35 s^{2}+50 s+24}$

The reduced order of the considered example 2 is reduced using case 1 and following the steps from Equation $(18-24)$.

$$
\begin{aligned}
G(s)= & \frac{s^{3}+7 s^{2}+24 s+24}{s^{4}+10 s^{3}+35 s^{2}+50 s+24} \\
& =\frac{0.0417 s^{3}+0.2917 s^{2}+s+1}{0.0417 s^{4}+0.4167 s^{3}+1.4583 s^{2}+2.0833 s+1}
\end{aligned}
$$

The routhain Table of Example 2 is given in Table 8 .

Table 8 Routhain Table for Higher-order system case-1

\begin{tabular}{|l|l|l|l|l|l|}
\hline & $\mathbf{1}$ & $\mathbf{2 . 0 8 3 3}$ & $\mathbf{1 . 4 5 8 3}$ & $\mathbf{0 . 4 1 6 7}$ & $\mathbf{0 . 0 4 1 7}$ \\
\hline$c_{0}=1$ & $\mathbf{1}$ & $\mathbf{1}$ & $\mathbf{0 . 2 9 1 7}$ & $\mathbf{0 . 0 4 1 7}$ & $\mathbf{0}$ \\
\hline$c_{1}=-1.8033$ & -1.0833 & -1.1666 & -0.375 & 2.9583 & 0 \\
\hline$c_{2}=1.090239$ & 1.090239 & 1.204776 & 3.409711 & 2.045174 & 0 \\
\hline$c_{3}=-1.06652$ & -1.06652 & 1.819816 & 1.590871 & -0.04546 & 0 \\
\hline$c_{4}=4.041693$ & 4.041693 & 3.146175 & 0.398955 & 0.044474 & \\
\hline$c_{5}=-5.27388$ & -5.27388 & -5.49505 & -1.6397 & & \\
\hline$c_{6}=5.492038$ & 5.492038 & 6.051207 & & & \\
\hline$c_{7}=-5.39036$ & -5.39036 & & & & \\
\hline
\end{tabular}

The values of $c_{0}, c_{1}, c_{2}, c_{3} \mathrm{~L}$ obtained from the routhani Table 8 is used to obtain the second order reduced ofrmat of the considered higher order in Equation (47-50) 


$$
\begin{gathered}
\hat{a}_{1}=C_{21}^{-1} \hat{c}_{2}=\left[\begin{array}{ll}
-c_{1} & -c_{0} \\
-c_{2} & -c_{1}
\end{array}\right]^{-1} \times\left[\begin{array}{l}
c_{2} \\
c_{3}
\end{array}\right]=\left[\begin{array}{l}
a_{12} \\
a_{13}
\end{array}\right]=\left[\begin{array}{cc}
-(-1.0833) & -(1) \\
-(1.090239) & -(1.0833)
\end{array}\right]^{-1} \times\left[\begin{array}{c}
1.090239 \\
-1.0833
\end{array}\right] \\
=\left[\begin{array}{ll}
13.0048 & 12.0048 \\
13.0881 & 13.0048
\end{array}\right] \times\left[\begin{array}{l}
1.090239 \\
-1.0833
\end{array}\right]=\left[\begin{array}{l}
1.3750 \\
0.3993
\end{array}\right] \\
\hat{a}_{2}=\hat{c}_{1}-C_{11} \hat{a}_{1}=\left[\begin{array}{l}
c_{0} \\
c_{1}
\end{array}\right]-\left[\begin{array}{cc}
0 & 0 \\
-c_{0} & 0
\end{array}\right] \times\left[\begin{array}{l}
a_{12} \\
a_{13}
\end{array}\right]=\left[\begin{array}{l}
a_{21} \\
a_{22}
\end{array}\right] \\
=\left[\begin{array}{c}
1 \\
-1.0833
\end{array}\right]-\left[\begin{array}{cc}
0 & 0 \\
-1 & 0
\end{array}\right] \times\left[\begin{array}{l}
1.3750 \\
0.3993
\end{array}\right]=\left[\begin{array}{l}
1.0000 \\
0.2917
\end{array}\right]
\end{gathered}
$$

The obtained reduced order is given in Equation (49)

$$
R_{M M}(s)=\frac{0.2917 s+1}{0.3993 s^{2}+1.3750 s+1}
$$

The obtained reduced-order using the SE is as follows in Equation (50)

$$
R_{S E}(s)=\frac{24 s+24}{35 s^{2}+50 s+24}
$$

\section{Considering the case-2}

Considering the fourth order from Equation (46) To reduce the higher-order using the steps from Equation (2627), offered routhain Table 2 . Table 9 is the routhain array for case- 2 .

Table 9: Routhain Table case-2

\begin{tabular}{|c|c|c|c|c|c|}
\hline & $\mathbf{1}$ & $\mathbf{1 0}$ & $\mathbf{3 5}$ & $\mathbf{5 0}$ & $\mathbf{2 4}$ \\
\hline$c_{0}=1$ & $\mathbf{1}$ & $\mathbf{7}$ & $\mathbf{2 4}$ & $\mathbf{2 4}$ & \\
\hline$c_{1}=-3$ & -3 & -11 & -26 & & \\
\hline$c_{2}=19$ & 19 & 79 & & & \\
\hline$c_{3}=-111$ & -111 & & & & \\
\hline
\end{tabular}

The values of $c_{0}, c_{1}, c_{2}, c_{3} \mathrm{~L}$ are used to obtain the reduced order

$$
\begin{aligned}
\hat{a}_{1}=C_{21}^{-1} \hat{c}_{2} & =\left[\begin{array}{ll}
-c_{1} & -c_{0} \\
-c_{2} & -c_{1}
\end{array}\right]^{-1} \times\left[\begin{array}{l}
c_{2} \\
c_{3}
\end{array}\right]=\left[\begin{array}{l}
a_{12} \\
a_{13}
\end{array}\right]=\left[\begin{array}{cc}
-(-3) & -(1) \\
-(19) & -(-3)
\end{array}\right]^{-1} \times\left[\begin{array}{c}
19 \\
-111
\end{array}\right] \\
& =\left[\begin{array}{ll}
-0.3000 & -0.1000 \\
-1.9000 & -0.3000
\end{array}\right] \times\left[\begin{array}{c}
19 \\
-111
\end{array}\right]=\left[\begin{array}{c}
5.4000 \\
-2.8000
\end{array}\right]
\end{aligned}
$$

Equation (53) gives the result that the reduced-order may be instable. For gaining the stable reduced order the we apply the pole placement technique[5] i.e. $-\mathrm{a}_{12}+\mathrm{a}_{13}=-1$

$$
\begin{aligned}
\hat{a}_{1}=C_{21}^{-1} \hat{c}_{2}=\left[\begin{array}{ll}
-c_{1} & -c_{0} \\
-c_{2} & -c_{1}
\end{array}\right]^{-1} \times\left[\begin{array}{l}
1 \\
1
\end{array}\right]=\left[\begin{array}{l}
a_{12} \\
a_{13}
\end{array}\right] \\
=\left[\begin{array}{cc}
-(-3) & -(1) \\
-1 & 1
\end{array}\right]^{-1} \times\left[\begin{array}{l}
19 \\
-1
\end{array}\right]=\left[\begin{array}{cc}
0.5000 & 0.5000 \\
-0.5000 & 1.5000
\end{array}\right] \times\left[\begin{array}{c}
19 \\
-1
\end{array}\right]=\left[\begin{array}{l}
9 \\
8
\end{array}\right] \\
\hat{a}_{2}=\hat{c}_{1}-C_{11} \hat{a}_{1}=\left[\begin{array}{c}
c_{0} \\
c_{1}
\end{array}\right]-\left[\begin{array}{cc}
0 & 0 \\
-c_{0} & 0
\end{array}\right] \times\left[\begin{array}{l}
a_{12} \\
a_{13}
\end{array}\right]=\left[\begin{array}{l}
a_{21} \\
a_{22}
\end{array}\right] \\
=\left[\begin{array}{c}
1 \\
-3
\end{array}\right]-\left[\begin{array}{cc}
0 & 0 \\
-1 & 0
\end{array}\right] \times\left[\begin{array}{l}
9 \\
8
\end{array}\right]=\left[\begin{array}{l}
1.0000 \\
6.0000
\end{array}\right]
\end{aligned}
$$

The reduced-order obtained using the case-1 is given in Equation (54)

$$
R_{M M}(s)=\frac{6 s+1}{8 s^{2}+9 s+1}
$$


The reduced-order obtained using the SE has given in Equation (55)

$$
R_{S E}(s)=\frac{s+1}{1.4583 s^{2}+2.0833 s+1}
$$

The reduced-order using the proposed mixed method is obtained and compared in Table 10

Table 10: Step response characteristics of obtained reduced order of Example 2 from Case 1, Case 2 and mixed methods with proposed mixed method

\begin{tabular}{|c|c|c|c|c|c|c|}
\hline \multirow{2}{*}{ Reduced $2^{\text {nd }}$ order } & \multicolumn{6}{|c|}{ Step reponse characteristics } \\
\hline & RT & ST & ST min & ST max & Peak & PT \\
\hline HOS Eq. (47) & 2.2603 & 3.9308 & 0.9019 & 0.9990 & 0.9990 & 6.8847 \\
\hline Eq.(51) & 2.2608 & 3.9472 & 0.9019 & 1.0000 & 1.0000 & 10.3230 \\
\hline Eq. (52) & 2.3001 & 3.3769 & 0.9081 & 1.0126 & 1.0126 & 5.1578 \\
\hline Eq. (57) & 8.2678 & 21.2741 & 0.9008 & 0.9977 & 0.9977 & 38.5913 \\
\hline Eq. (58) & 2.3000 & 3.3768 & 0.9081 & 1.0126 & 1.0126 & 5.1578 \\
\hline$R_{\frac{M M}{S E}}(s)=\frac{0.2917 s+1}{35 s^{2}+50 s+24}$ & 3.2014 & 1.8650 & 0.0376 & 0.0419 & 0.419 & 7.1564 \\
\hline$R_{\frac{S E}{M M}}(s)=\frac{24 s+24}{0.3993 s^{2}+1.3750 s+1}$ & 0.8365 & 1.3940 & 21.6275 & 24.0722 & 24.0722 & 2.5520 \\
\hline$R_{\frac{M M}{S E} C 2}(s)=\frac{6 s+1}{1.4583 s^{2}+2.0833 s+1}$ & 0.2322 & 6.7650 & 0.9010 & 2.3587 & 2.3587 & 1.5473 \\
\hline$R_{\frac{S E}{M M} C 2}(s)=\frac{s+1}{8 s^{2}+9 s+1}$ & 14.8576 & 26.4306 & 0.9027 & 0.9993 & 0.9993 & 48.6617 \\
\hline$R_{\frac{S E C 1}{M M C 2}}(s)=\frac{s+1}{0.3993 s^{2}+1.3750 s+1}$ & 0.8365 & 1.3940 & 0.9011 & 1.3008 & 1.0030 & 2.5520 \\
\hline
\end{tabular}

Figure 4 gives the step response characteristics of the proposed reduced-order and reduced-order using the given methodologies in the manuscript. The proposed reduced-order attains the rise time in the shortest times period, which is 0.8365 and settles early as compared with others, which are 1.3940 after that, the response line follows the original system path.

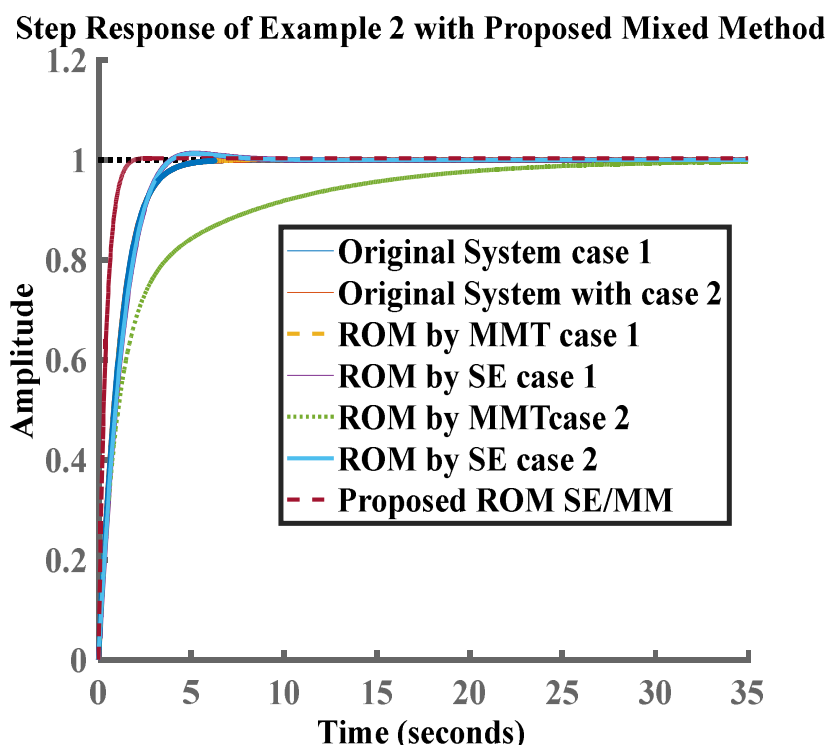

Figure 4: Step response Characteristics of Higher Order with proposed reduced-order 
The proposed reduced-order pole-zero plotting with the original higher-order system, second-order reduced using the moment matching, $2^{\text {nd }}$ order reduced using the SE, $2^{\text {nd }}$ order using the Improved $M M, 2^{\text {nd }}$ order using the improved SE and proposed reduced-order using the SE and Moment matching is given in Figure 5.

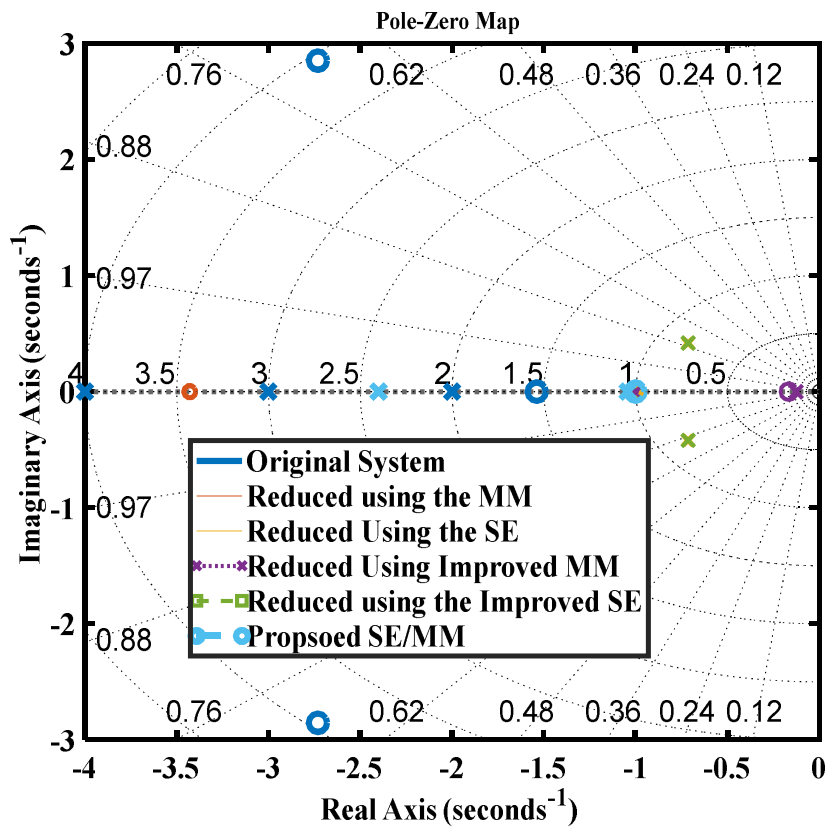

Figure 5: Pole Zero plot of Original system 2, reduced-order using the MM, SE, improved MM, the improved SE, the proposed reduced-order system using SE/MM

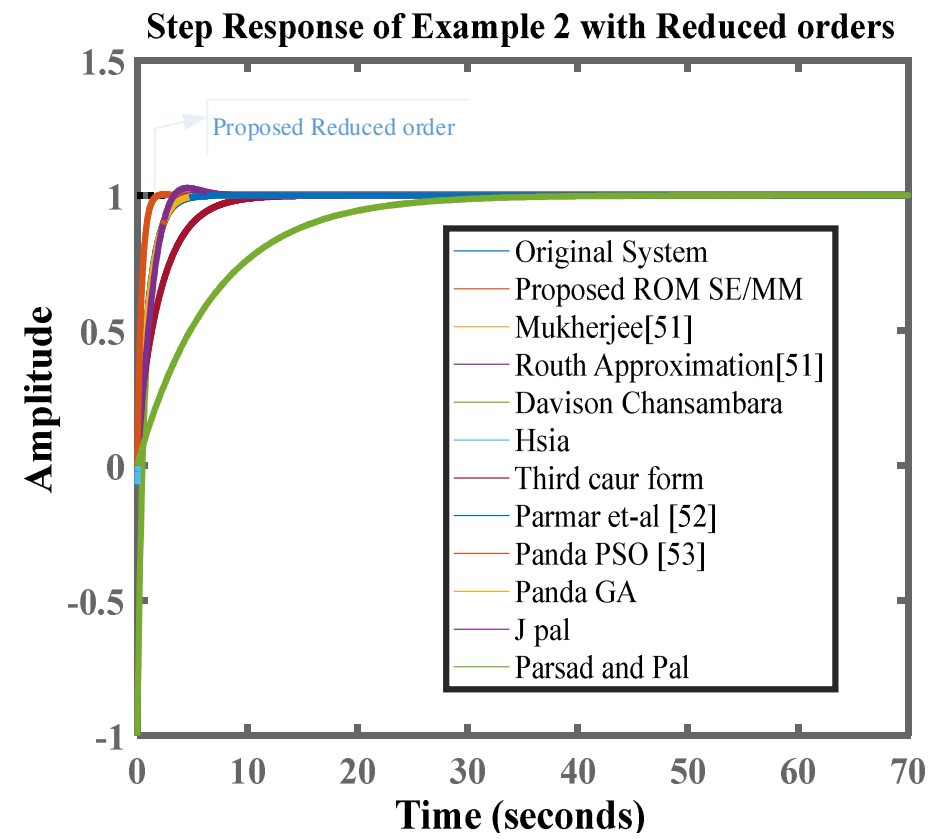

Figure 6: Comparative Step response characteristics of HOS with proposed reduced-order and reducedorder from literature

The step response comparative analysis of the HOS 2 is in table 9. The result obtained is competitive with the response from literature and it can be observed from the step response characteristics Figure 6. The response indices of system 2 are available in Table 11 which is also competitive, however, the ITAE, IAE and ISE are calculated and comparison is given in Table 12. 
Table 11: Step response characteristics of HOS with proposed reduced and from reduced from literature

\begin{tabular}{|c|c|c|c|c|c|c|c|}
\hline \multirow[b]{2}{*}{ References } & \multirow[b]{2}{*}{ Reduced $2^{\text {nd }}$ order } & \multicolumn{6}{|c|}{ Step reponse characteristics } \\
\hline & & $\mathbf{R T}$ & ST & $\begin{array}{c}\text { ST } \\
\text { min }\end{array}$ & $\begin{array}{c}\text { ST } \\
\text { max }\end{array}$ & Peak & PT \\
\hline Equation (47) & Original condition 1 & $\begin{array}{l}2.260 \\
3\end{array}$ & $\begin{array}{l}3.930 \\
8\end{array}$ & $\begin{array}{l}0.90 \\
19\end{array}$ & $\begin{array}{l}0.99 \\
90\end{array}$ & $\begin{array}{l}0.999 \\
0\end{array}$ & $\begin{array}{l}6.884 \\
7\end{array}$ \\
\hline Proposed & $\frac{s+1}{0.3993 s^{2}+1.3750 s+1}$ & $\begin{array}{l}0.836 \\
5\end{array}$ & $\begin{array}{l}1.394 \\
0\end{array}$ & $\begin{array}{l}0.90 \\
11\end{array}$ & $\begin{array}{l}1.30 \\
08\end{array}$ & $\begin{array}{l}1.003 \\
0\end{array}$ & $\begin{array}{l}2.552 \\
0\end{array}$ \\
\hline S. Mukherjee[51] & $\frac{0.800003 s+3}{s^{2}+3 s+2}$ & $\begin{array}{l}2.484 \\
2\end{array}$ & $\begin{array}{l}4.290 \\
8\end{array}$ & $\begin{array}{l}1.35 \\
11\end{array}$ & $\begin{array}{l}1.49 \\
85\end{array}$ & $\begin{array}{l}1.498 \\
5\end{array}$ & $\begin{array}{l}7.322 \\
2\end{array}$ \\
\hline $\begin{array}{l}\text { Routh } \\
\text { Approximation } \\
\text { [Hutton and } \\
\text { Friedland][51] }\end{array}$ & $\frac{0.7947(s+1)}{s^{2}+1.6557 s+0.7947}$ & $\begin{array}{l}2.320 \\
7\end{array}$ & $\begin{array}{l}3.710 \\
5\end{array}$ & $\begin{array}{l}0.90 \\
55\end{array}$ & $\begin{array}{l}1.00 \\
22\end{array}$ & $\begin{array}{l}1.002 \\
2\end{array}$ & $\begin{array}{l}6.174 \\
7\end{array}$ \\
\hline $\begin{array}{l}\text { Davison } \\
\text { chansambara[51] }\end{array}$ & $\frac{2-s^{2}}{s^{2}+3 s+2}$ & $\begin{array}{l}1.696 \\
4\end{array}$ & $\begin{array}{l}3.256 \\
9\end{array}$ & $\begin{array}{l}0.80 \\
65\end{array}$ & $\begin{array}{l}0.99 \\
83\end{array}$ & 1 & 0 \\
\hline Hsia[51] & $\frac{-0.0694 s^{2}+0.8333 s+2}{s^{2}+3 s+2}$ & $\begin{array}{l}2.217 \\
9\end{array}$ & $\begin{array}{l}3.937 \\
5\end{array}$ & $\begin{array}{l}0.89 \\
55\end{array}$ & $\begin{array}{l}0.99 \\
93\end{array}$ & $\begin{array}{l}0.999 \\
3\end{array}$ & $\begin{array}{l}7.322 \\
2\end{array}$ \\
\hline $\begin{array}{l}\text { Third } \quad \text { Cauer } \\
\text { Form[51] }\end{array}$ & $\frac{s+2.3014}{s^{2}+5.7946 s+2.3014}$ & $\begin{array}{l}4.960 \\
8\end{array}$ & $\begin{array}{l}8.834 \\
2\end{array}$ & $\begin{array}{l}0.90 \\
07\end{array}$ & $\begin{array}{l}0.99 \\
97\end{array}$ & $\begin{array}{l}0.999 \\
7\end{array}$ & $\begin{array}{l}18.34 \\
97\end{array}$ \\
\hline J. Pal & $\frac{16.0008 s+24}{30 s^{2}+42 s+24}$ & $\begin{array}{l}2.198 \\
7\end{array}$ & $\begin{array}{l}5.570 \\
0\end{array}$ & $\begin{array}{l}0.90 \\
79\end{array}$ & $\begin{array}{l}1.02 \\
69\end{array}$ & $\begin{array}{l}1.026 \\
9\end{array}$ & $\begin{array}{l}4.539 \\
4\end{array}$ \\
\hline Prasad and Pal & $\frac{s+34.2465}{s^{2}+239.8082 s+34.2465}$ & $\begin{array}{l}15.37 \\
60\end{array}$ & $\begin{array}{l}27.35 \\
30\end{array}$ & $\begin{array}{l}0.90 \\
04\end{array}$ & $\begin{array}{l}1.00 \\
0\end{array}$ & $\begin{array}{l}1.000 \\
0\end{array}$ & $\begin{array}{l}73.80 \\
23\end{array}$ \\
\hline
\end{tabular}

Table 12: Response indices of proposed reduced and from reduced order from literature

\begin{tabular}{|l|c|c|c|c|}
\hline \multirow{2}{*}{ Reference } & Reduced -Order & \multicolumn{2}{c|}{ Response Indices Error } \\
\cline { 4 - 5 } & $\frac{s^{2}+1}{0.3993 s^{2}+1.3750 s+1}$ & $\mathbf{1 . 6 8 1}$ & $\mathbf{0 . 7 0 8 2}$ & $\mathbf{0 . 1 8 5}$ \\
\hline Proposed & $\frac{0.800003 s+2}{s^{2}+3 s+2}$ & 23.05 & 3.735 & 1.713 \\
\hline $\begin{array}{l}\text { S. Mukherjee } \\
\text { [51] }\end{array}$ & $\frac{0.7947(s+1)}{s^{2}+1.6557 s+0.7947}$ & 0.2054 & 0.04649 & 0.0003783 \\
\hline $\begin{array}{l}\text { Routh Approximation } \\
\text { [51] }\end{array}$ & $\frac{2-s^{2}}{s^{2}+3 s+2}$ & 0.5764 & 0.4167 & 0.2202 \\
\hline $\begin{array}{l}\text { Davison Chansambara } \\
\text { 51] }\end{array}$ & $\frac{-0.0694 s^{2}+0.8333 s+2}{s^{2}+3 s+2}$ & 0.08528 & 0.04164 & 0.001133 \\
\hline $\begin{array}{l}\text { Hsia[51] } \\
\text { Third Cauer Form[51] }\end{array}$ & $\frac{s^{2}+2.3014}{s^{2}+5.7946 s+2.3014}$ & 4.187 & 0.9567 & 0.1472 \\
\hline $\begin{array}{l}\text { Parmar et-al [52] } \\
\text { J. Pal }\end{array}$ & $\frac{0.6667 s+4}{s^{2}+5 s+4}$ & 0.06627 & 0.02612 & $2.64337 \mathrm{e}-04$ \\
\hline Prasad and Pal & $\frac{16.0008 s+24}{30 s^{2}+42 s+24}$ & 0.9679 & 0.2534 & 0.1188 \\
\hline
\end{tabular}


The response indices from the proposed ITAE is 1.681 , IAE is 0.7082 and ISE is 0.185 which is better than the $3^{\text {rd }}$ Cauer form, Prasad and Pal, S Mukherjee and competitive with other reduced orders from literature.

\section{Conclusion}

The rigorous study of a new method for MOR has been carried out in this article. The technique unifies of two strategies i.e time moment matching with the concept of modification in Routhain array and stability equation. The modifications in the routhain array from descending to ascending way of coefficient of "s" make systematic changes in the value of $c_{0}, c_{1}, c_{2}, c_{3} \mathrm{~L}$. The change in values $c_{0}, c_{1}, c_{2}, c_{3} \mathrm{~L}$ results in the change in reduced order. The proposed strategy applied to SISO LTI systems of sixth and fourth order. The succession of the approach is justified by obtaining the approximation error and comparing it with the result available in the literature. The approach of the proposed mixed-method results successfully with conditions $b_{0}=a_{0}$ or $b_{0}=a_{0}=1$ and $b_{m}=a_{n}$ or $b_{n}=a_{n}=1$. The settling min, settling-max and peak of the diminished system are very close to the original system.

\section{References}

[1] Y. Shamash, "Stable reduced-order models using Padé-type approximations," IEEE Transactions on Automatic Control, vol. 19, no. 5, pp. 615-616, 1974.

[2] M. Lal and R. Mitra, "Simplification of Large System Dynamics Using a Moment Evaluation Algorithm," IEEE Transcations on Automatic Control, vol. 19, no. 5, pp. 602-603, 1975.

[3] R. Parthasarathy and H. Singh, "A mixed method for the simplification of large system dynamics," Proceedings of the IEEE, vol. 65, no. 11, pp. 1604-1605, 1977.

[4] M. Hutton and B. Friedland, "Routh approximations for reducing order of linear, time-invariant systems," IEEE Transactions on Automatic Control, vol. 20, no. 3, pp. 329-337, 1975.

[5] D. K. Sambariya and A. K. Sharma, "An effificent apprach for stability preservation in model order reduction using moment matching technique," in International Conference on Computer, Communications and Electronics (Comptelix), Jaipur, 2017, pp. 478-483: IEEE.

[6] T. C. Chen, C. Y. Chang, and Han K. W., "Reduction of Transfer Functions by the Stability-Equation Method," Journal of the Franklin Institute, vol. 308, no. 4, pp. 389-404, 1979/10/01 1979.

[7] G. Langholz and D. Feinmesser, "Model reduction by Routh approximations," International Journal of Systems Science, vol. 9, no. 5, pp. 493-496, 1978/05/01 1978.

[8] A. M. Davidson and T. N. Lucas, "Linear-system reduction by continued-fraction expansion about a general point," Electronics Letters, vol. 10, no. 14, pp. 271-273, 1974.

[9] C. Hwang and C. F. Yung, "A generalized Cauer third continued-fraction expansion and its application to model reduction," Journal of the Chinese Institute of Engineers, vol. 13, no. 6, pp. 633-653, 1990/09/01 1990.

[10] R. Parthasarathy and K. N. Jayasimha, "System reduction using stability-equation method and modified Cauer continued fraction," Proceedings of the IEEE, vol. 70, no. 10, pp. 1234-1236, 1982.

[11] T. C. Chen, C. Y. Chang, and K. W. Han, "Model reduction using the stability-equation method and the continued-fraction method," International Journal of Control, vol. 32, no. 1, pp. 81-94, 1980/07/01 1980.

[12] J. Pal "Stable reduced-order Pade approximants using the Routh-Hurwitz array," Electronics Letters, vol. 15, no. 8, pp. 225-226, 1979.

[13] J. Pal and L. M. Ray, "Stable padé approximants to multivariable systems using a mixed method," Proceedings of the IEEE, vol. 68, no. 1, pp. 176-178, 1980.

[14] L. Shieh and Y. Wei, "A mixed method for multivariable system reduction," IEEE Transactions on Automatic Control, vol. 20, no. 3, pp. 429-432, 1975.

[15] L. S. Shieh and Y. J. Wei, "Mixed method for reduction of multivariable systems with various inputs and outputs," Proceedings of the Institution of Electrical Engineers, vol. 122, no. 10, pp. 1159-1160, 1975.

[16] T. C. Chen, C. Y. Chang, and K. W. Han, "Stable reduced-order Pad ̃®@ approximants using stabilityequation method," Electronics Letters, vol. 16, no. 9, pp. 345-346, 1980.

[17] J. Pal, "Improved Pade approximants using stability equation method," Electronics Letters, vol. 19, no. 11, pp. 426-427, 1983. 
[18] N. Singh, R. Prasad, and H. O. Gupta, "Reduction of Linear Dynamic Systems using Routh Hurwitz Array and Factor Division Method," IETE Journal of Education, vol. 47, no. 1, pp. 25-29, 2006/01/01 2006.

[19] G. Parmar, R. Prasad, and S. Mukherjee, "A Mixed Method for Large-Scale Systems Modelling using Eigen Spectrum Analysis and Cauer Second Form," IETE Journal of Research, vol. 53, no. 2, pp. 93102, 2007/03/01 2007.

[20] D. K. Sambariya, A. K. Sharma, and T. Gupta, "Order Reduction of Air Core Transformer Using Continued Fraction," Journal of Engineering Science and Technology (JESTEC), vol. 14, no. 1, pp. 253264, 1-3-2019 2019.

[21] G. Saraswathi, K. A. G. Rao, and J. Amarnath, "A mixed method for order reduction of interval systems," in 2007 International Conference on Intelligent and Advanced Systems, 2007, pp. 1042-1046.

[22] A. Sikander and R. Prasad, "Linear time-invariant system reduction using a mixed methods approach," Applied Mathematical Modelling, vol. 39, no. 16, pp. 4848-4858, 2015.

[23] D. Sambariya and A. Rajawat, "Model order reduction by routh stability array with stability equation method for siso and mimo systems," Universal Journal of Engineering Science, vol. 4, no. 1, pp. 1-13, 2016.

[24] D. K. Sambariya and H. Manohar, "Model order reduction by differentiation equation method using with Routh array Method," in 2016 10th International Conference on Intelligent Systems and Control (ISCO), 2016, pp. 1-6.

[25] L. Hongxing, L. Jinshi, and Y. Hongshu, "Model Reduction Using the Genetic Algorithm and Routh Approximations," Journal of Systems Engineering and Electronics, vol. 16, no. 3, pp. 632-639, 2005.

[26] Z. W. Wang and X. Q. Liu, "Model Order Reduction Based on Particle Swarm Optimization," in 2006 8th international Conference on Signal Processing, 2006, vol. 4, p. 1.

[27] G. Parmar, S. Mukherjee, and R. Prasad, "Reduced order modeling of linear dynamic systems using particle swarm optimized eigen spectrum analysis," Int. J. Computer and Mathematical Science, vol. 1, no. 31, pp. 45-52, 2007.

[28] G.Parmar, S. Mukherjee, and R. Prasad, "Reduced order modeling of Linear MIMO systems using Genetic algorithm," Int. J. Simul. Model, vol. 6, no. 3, pp. 173-184, 2007.

[29] G. Parmar, S. Mukherjee, and R. Prasad, "Relative mapping errors of linear time invariant systems caused by particle swarm optimized reduced order model," World Academy of Science and Technology, pp. 336342, 2007.

[30] G. Parmar, R. Prasad, and S. Mukherjee, "Order reduction of linear dynamic systems using stability equation method and GA," International Journal of Computer, Information, and Systems Science, and Engineering, vol. 1, no. 1, pp. 26-32, 2007.

[31] S. Panda, S. K. Tomar, R. Prasad, and C. Ardil, "Reduction of Linear Time -Invarient Systems Using Routh-Approximation and PSo," International Journal of Applied Mathematics and Computer Sciences, vol. 5, no. 2, pp. 82-89, 2009.

[32] C. B. Vishwakarma and R. Prasad, "MIMO System Reduction Using Modified Pole Clustering and Genetic Algorithm," Modelling and Simulation in Engineering, vol. 2009, p. 5, 2009, Art. no. 540895.

[33] J. S. Yadav, N. P. Patidar, J. Singhai, and S. Panda, "Differential Evolution algorithm for model reduction of SISO discrete systems," in 2009 World Congress on Nature \& Biologically Inspired Computing (NaBIC), 2009, pp. 1053-1058.

[34] D. K. Kumar, S. Nagar, and S. Bharadwaj, "Model order reduction of SISO and MIMO systems based on genetic algorithm," in International Conference on Automation, Robotics and Control Systems, 2010, pp. 97-104.

[35] J. C. Bansal, H. Sharma, and K. V. Arya, "Model Order Reduction of Single Input Single Output Systems Using Artificial Bee Colony Optimization Algorithm," in Nature Inspired Cooperative Strategies for Optimization (NICSO 2011)Berlin, Heidelberg: Springer Berlin Heidelberg, 2011, pp. 85-100.

[36] S. R. .Desai and R. Prasad, "A new approach to order reduction using stability equation and big bang big crunch optimization," Systems Science \& Control Engineering: An Open Access Journal, vol. 1, no. 1, pp. 20-27, 2013.

[37] H. Khageh and S. Balochian, "Hybrid PSO and GA for model order reduction of large scale linear systems," ACTA ELECTROTECHNICA mediamira science publisher, vol. 54, no. 2, pp. 114-119, 2013.

[38] H. Nasiri Soloklo and M. M. Farsangi, "Chebyshev rational functions approximation for model order reduction using harmony search," Scientia Iranica, vol. 20, no. 3, pp. 771-777, 2013/06/01/ 2013.

[39] H. N. Soloklo and M. M. Farsangi, "Multi-objective weighted sum approach model reduction by RouthPade approximation using harmony search," Turkish Journal of Electrical Engineering \& Computer Sciences, vol. 21, no. Sup. 2, pp. 2283-2293, 2013. 
[40] H. Nasiri Soloklo, \&, and M. Maghfoori Farsangi, "Model Order Reduction by Legendre Expansion Using Harmony Search Algorithm," Majlesi Journal of Electrical Engineering, vol. 9, no. 1, pp. 25-35, 2014.

[41] D. Sambariya and O. Sharma, "Model order reduction using routh approximation and cuckoo search algorithm," Journal of Automation and Control, vol. 4, no. 1, pp. 1-9, 2016.

[42] O. Alsmadi, A. Al-Smadi, and E. Gharaibeh, "Design of reduced order models for multi-time-scale systems via firefly optimization," in 2017 14th International Multi-Conference on Systems, Signals \& Devices (SSD), 2017, pp. 688-692.

[43] D. K. Sambariya and T. Gupta, "An Application of Flower Pollination Algorithm in Model Order Reduction of LTI Systems," American Journal of Electrical and Electronic Engineering, vol. 6, no. 3, pp. 77-84, 2018/7/26 2018 .

[44] A.K.Sharma and D.K.Sambariya, "Mixed Method Application in Order Reduction of Discrete System," in 2018 3rd IEEE International Conference on Recent Trends in Electronics, Information \& Communication Technology (RTEICT), Banglore, 2018, pp. 1776-1780.

[45] A. K. Prajapati, R. Prasad, and J. Pal, "Contribution of Time Moments and Markov Parameters in Reduced Order Modeling," in 2018 3rd International Conference for Convergence in Technology (I2CT), 2018, pp. 1-7.

[46] A. K. Sharma; and D. K. Sambariya, "Analysis of Novel Hybrid Method for Linear Higher Order Reduction " presented at the International Conference on Electrical, Communication, Electronics, Instrumentation and Computing (ICECEIC), Sri Chandrasekharendra Saraswathi Viswa Mahavidyalaya, Sri Jayendra Saraswathi Street, Enathur, Kanchipuram, Tamil Nadu, India - 631 561., 30th \& 31st January 20192019.

[47] D. K. Sambariya and O. Sharma, "Model Order Reduction Using Routh Approximation and Cuckoo Search Algorithm," Journal of Automation and Control, vol. 4, no. 1, pp. 1-9, 2016.

[48] D. K. Sambariya and H. Manohar, "Model order reduction by integral squared error minimization using bat algorithm," in 2015 2nd International Conference on Recent Advances in Engineering \& Computational Sciences (RAECS), 2015, pp. 1-7.

[49] S. Lavania and D. Nagaria, "Pade approximation based moment matching technique for model order reduction," in 2015 International Conference on Computer, Communication and Control (IC4), 2015, pp. 1-4.

[50] S. Lavania and D. Nagaria, "Eigen spectrum based moment matching technique for model order reduction," in 2015 39th National Systems Conference (NSC), 2015, pp. 1-5.

[51] S. Mukherjee and R. N. Mishra, "Order reduction of linear systems using an error minimization technique," Journal of the Franklin Institute, vol. 323, no. 1, pp. 23-32, 1987/01/01/ 1987.

[52] G. Parmar, S. Mukherjee, and R. Prasad, "System reduction using factor division algorithm and eigen spectrum analysis," Applied Mathematical Modelling, vol. 31, no. 11, pp. 2542-2552, 2007/11/01/ 2007. 